Article

\title{
An Innovative Design of Regional Air Conditioning to Increase Automobile Cabin Energy Efficiency
}

\author{
Cheng-Jung Yang ${ }^{1}$, Tzu-Chun Yang ${ }^{2}$, Po-Tuan Chen ${ }^{3,4, *(1)}$ and K. David Huang ${ }^{2, *}$ \\ 1 Department of Mechanical Engineering, National Pingtung University of Science and Technology, \\ Pingtung 91201, Taiwan; cjyang@mail.npust.edu.tw \\ 2 Department of Vehicle Engineering, National Taipei University of Technology, Taipei 10608, Taiwan; \\ subseven520@gmail.com \\ 3 Center for Condensed Matter Sciences, National Taiwan University, Taipei 10617, Taiwan \\ 4 Center of Atomic Initiative for New Materials, National Taiwan University, Taipei 10617, Taiwan \\ * Correspondence: r92222019@ntu.edu.tw (P.-T.C.); kdavidh@ntut.edu.tw (K.D.H.); \\ Tel.: +886-2-33661776 (P.-T.C.); +886-2-2771-2171 (ext. 3676) (K.D.H.)
}

Received: 16 May 2019; Accepted: 16 June 2019; Published: 19 June 2019

\begin{abstract}
With the goal of increasing energy efficiency and passenger comfort in an automobile cabin, we developed a regional air-conditioning design to control cold air in specific regions, and an air management strategy that can keep air circulation when the car engine cuts out. According to computational simulations, an air velocity of $2 \mathrm{~m} / \mathrm{s}$ was adopted, which could form an independent flow field space in the cabin with a temperature gap of $7^{\circ} \mathrm{C}$ according to the user's needs. The designed regional air-conditioning and circulation system could create independent flow field spaces with temperature differences. Inlet air volume demand was also reduced by $60 \%$ and blower power by $53 \mathrm{~W}$. In addition, the cabin ventilation system led air exchange rate reached $89 \%$ per hour. In 20 min of exposure under sun, the system could lower the cabin temperature by $12.3^{\circ} \mathrm{C}$.
\end{abstract}

Keywords: energy saving; automobile cabin; regional air-conditioning; parking ventilation

\section{Introduction}

Air-conditioning (AC) system performance is one of the major concerns related to automobile energy consumption [1]. To date, most automobile manufacturers prioritize customer comfort by using windpipe allocation and server motor control to develop automatic temperature controllers [2-4]. The aforementioned technique used the temperature differences at each air inlet to conduct $\mathrm{AC}$ adjustment. However, as the length of AC operating time increases and the flow field in the cabin reaches stability, such methods cannot change the temperature of each zone in an energy-saving manner, because this results in a greater temperature difference in the inlet, which causes unnecessary energy waste. Therefore, current automobile AC systems still have room for improvement in terms of cabin airflow and temperature management [5-7]. Besides, maintaining the cabin at a mild temperature is essential even when the automobile is off [8]. To do so, a common method is to reduce the cabin temperature using sun control window films. Several studies reported the development of solar-powered ventilation systems $[9,10]$. However, this system can only provide power to the blower to intake air from outside; it does not conduct reasonable control over the airflow in the cabin and thus cannot effectively remove heat.

Furthermore, Kwon et al. [11] redesigned the hardware of heating, ventilation, and air conditioning (HVAC). They added wind direction control devices and choke valves, enabling wind flows to be directed to the zone inlet selected by the driver, thereby preventing wind from being directed to inlets 
where there was no passenger. For the software design, they introduced temperature control strategies. The power of the electric compressor of a car with this new technology is $17 \%$ lower than that of cars without the new technology, and mileage is increased by $9 \%$. Tabei et al. [12] developed an energy saving air flow control system, nominated S-FLOW, that could open a specific inlet selected by the driver. Additionally, because the amount of wind required was reduced, the noise produced by the blower was also reduced. Wang et al. [13] proposed the concept of localized cooling, and they used an electronic variable compressor, thermal expansion valve, brushless blower, and dummies to experiment on thermal comfort. Their results revealed that although the effectiveness of localized cooling was superior to existing HVAC systems, most inlets generated large airflow volumes that caused a discomforting sensation for those nearby. An inlet near the face could cause xerophthalmia. Then, Jeffers et al. [14] tested a cabin ventilation system, solar radiation reduction measure, and regional AC system on a Ford Focus electric vehicle. Specifically, regarding the cabin ventilation, the existing HVAC blower was tested using two controlling strategies [i.e., just-in-time (JIT) and temperature control (T-ctrl)].

Theoretical models of passenger thermal comfort have been studied [15-18], as well as factor evaluation [19], fluidic design [20,21], simulation analysis [22-24], experiment [25,26], and management strategy formulation research [27]. Ever-increasing demands in low-carbon emission vehicles [28-32] have propelled AC development considering energy efficiency. Therefore, we introduce a novel structural design of an air outlet to approach regional AC and air exchange. This study adopted the theory of computation fluid dynamics (CFD) to simulate the spatial flow field in the cabin. Thus, the relevance of a spatial flow field with suitable inlet, outlet, and sensor devices was then elucidated. Subsequently, cabin comfort was enhanced practically by applying: (1) an individual regional AC. Generally, the convection effect is stronger than the diffusion effect in a cabin flow field. Accordingly, air management was conducted using this principle to achieve energy conservation and enhance passenger comfort. (2) Cabin comfort was also enhanced by applying a parking ventilation and heat exclusion system. When the vehicle is idling, the inlets and outlets inside the cabin were adjusted to reduce the heat load generated by high-temperature sunlight or atmosphere exposure, thereby preventing vehicle occupants from experiencing fatal heatstroke.

\section{Materials and Methods}

A commercial automobile (CMC Zinger, China Motor Corp., Taoyuan, Taiwan) was utilized as the experimental subject. Computer-aided design (CAD) and CFD were adopted during numerical simulation, of which the results were applied to the design of cabin flow field. The designed regional $\mathrm{AC}$ and parking ventilation was then verified through tests to ensure favorable air quality and safe monitoring.

\subsection{Numerical Simulation Analysis}

\subsubsection{Vehicle Modeling}

This study ran the CAD software to create a three-dimensional (3D) model of the cabin (Figure 1). The cabin was $3.55 \mathrm{~m} \times 1.38 \mathrm{~m} \times 1.4 \mathrm{~m}$ (length $\times$ width $\times$ height), with a capacity of $5.145 \mathrm{~m}^{3}$. Next, the ANSYS/FLUENT Design Modeler software [33] was used to perform CAD geometry modification and simplification on the cabin model for the convenience of the subsequent fluid mechanics simulation, calculation, and analysis. 


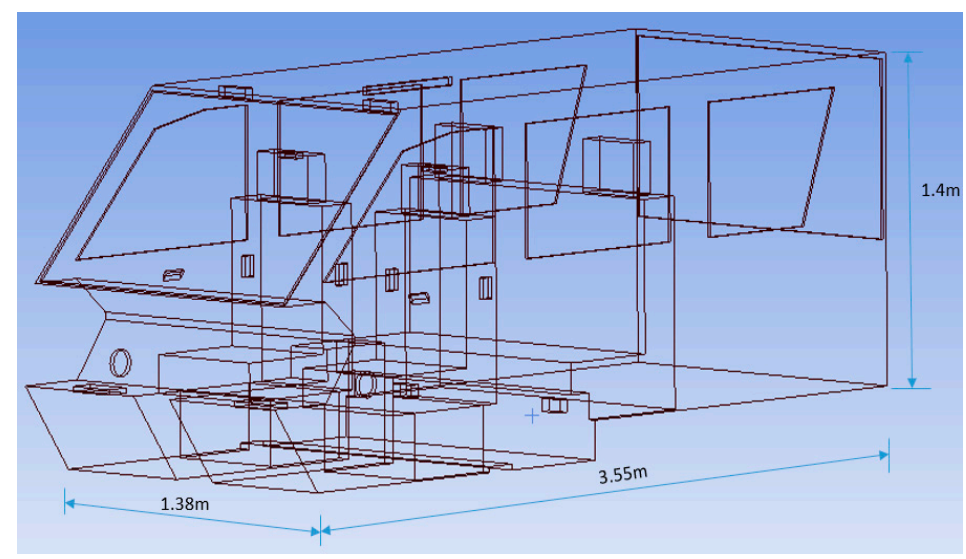

Figure 1. Cabin 3D model.

\subsubsection{Mathematical Model}

In the present study, a standard $k-\varepsilon$ turbulence model was adopted to conduct a flow field analysis in an automobile cabin [34]. To fully accommodate the physical characteristics and corresponding calculation time, the following assumptions were made: (1) the effects of gravity and buoyancy on the flow field are accounted for; (2) the fluid is a Newtonian fluid; (3) the flow field is a transient, turbulent flow; (4) viscous dissipation is overlooked; and (5) the fluid at the inlet is moving at a uniform velocity. The dominance equations for numerical analysis in this study are as follows:

(a) Continuity equation:

$$
\frac{\partial p}{\partial t}+\frac{\partial_{p u_{i}}}{\partial x_{i}}=0
$$

(b) Momentum equation:

$$
\frac{\partial_{p u_{i}}}{\partial t}+\frac{\partial_{p u_{i} p u_{j}}}{\partial x_{i}}=-\frac{\partial P}{\partial x_{i}}\left[\mu\left(\frac{\partial u_{i}}{\partial x_{j}}+\frac{\partial u_{j}}{\partial x_{i}}\right)\right]
$$

(c) Energy equation:

$$
\frac{\partial}{\partial t}(\rho E)+\frac{\partial}{\partial x_{i}}\left[u_{i}(\rho E+p)\right]=\frac{\partial}{\partial x_{i}}\left(k_{e f f} \frac{\partial T}{\partial x_{i}}+u_{j}\left(\tau_{i j}\right)_{e f f}\right)
$$

where $E$ is the total energy, $k_{e f f}$ is the effective thermal conductivity, and $\left(\tau_{i j}\right)_{e f f}$ is the effective stress tensor, whose definition is as follows:

$$
\left(\tau_{i j}\right)_{e f f}=\mu_{e f f}\left(\frac{\partial \overline{u_{i}}}{\partial x_{i}}+\frac{\partial \overline{u_{j}}}{\partial x_{i}}\right)-\frac{2}{3} \mu_{e f f} \frac{\partial \overline{u_{l}}}{\partial x_{i}} \delta_{i j}
$$

$\kappa_{e f f}$ denotes the turbulent thermal conductivity coefficient, which is defined as follows:

$$
\kappa_{e f f}=\kappa_{1}+\frac{c_{p} \mu_{t}}{\mathrm{P}_{r t}}
$$

(d) Buoyancy:

When density changes, fluid moves due to buoyancy. This study used the Boussinesq buoyancy approximation to derive the movement, which is defined as follows:

$$
\begin{gathered}
u \frac{\partial u}{\partial x}+v \frac{\partial u}{\partial x}=-\frac{g}{\rho}\left(\rho_{\infty}-\rho\right)+\frac{\mu}{\rho} \frac{\partial^{2} \mu}{\partial^{2} y} \\
\beta=-\left.\frac{1}{\rho} \frac{\partial p}{\partial t}\right|_{p} \approx-\frac{1}{p} \frac{p_{\infty}-p}{T_{\infty}-T}
\end{gathered}
$$


Equation (6) shows that the coefficient of thermal expansion substantially influences the fluid density change and the degree of fluidity, and Equation (7) shows that gas $\beta$ is the reciprocal of temperature $T$; the definition of $\beta$ is as follows:

$$
\beta=\frac{1}{\rho} \frac{\rho}{R T^{2}}=\frac{1}{T}
$$

(e) External radiation heat:

This study adopted the fair weather condition [33], and the transmissivity of solar radiation is as follows:

$$
\begin{gathered}
T(\theta, \lambda)=\mathrm{T}(0, \lambda) \operatorname{Tre} f(\theta) \\
\operatorname{Tref}(\theta)=a 0+a 1 \cos (\theta)+a^{2} \cos \left(\theta^{2}\right)+a^{3} \cos \left(\theta^{3}\right)+a^{4} \cos \left(\theta^{4}\right)
\end{gathered}
$$

The reflectivity of solar radiation is defined as follows:

$$
\begin{gathered}
R(\theta, \lambda)=R(0, \lambda)[1-\operatorname{Rref}(\theta)]+\operatorname{Rref}(\theta) \\
\operatorname{Rref}(\theta)=b 0+b 1 \cos (\theta)+b^{2} \cos \left(\theta^{2}\right)+b^{3} \cos \left(\theta^{3}\right)+b^{4} \cos \left(\theta^{4}\right) \\
E d n=\frac{A}{\frac{B}{e^{\sin \beta}}}
\end{gathered}
$$

In Equation (13), $A$ is the solar radiation parameter when the air mass is zero; $B$ is the atmospheric extinction coefficient when the air mass is zero; $\beta$ is the degree to which the Sun is above the horizon (deg); and $E d n$ is the direct radiation of the sun on the Earth during fair weather conditions. The equation for solar radiation shining vertically on a surface is as follows:

$$
E d=C \times Y \times E d n
$$

$C$ is a constant, and $Y$ is the ratio of diffused radiation on a vertical surface compared with a horizontal surface. Thus, $E d$ becomes:

$$
E d=C E d n \frac{(1+\cos \varepsilon)}{2}
$$

where $\varepsilon$ is the obliquity of the Earth's surface. Therefore, the ground reflection of the solar radiation is defined as follows:

$$
E r=E d n(C+\sin \beta) \rho_{g} \frac{(1-\cos \varepsilon)}{2}
$$

where $\rho_{g}$ is the rate of ground reflection.

(f) Turbulence $k-\varepsilon$ equation

Turbulence kinetic $k$ can be obtained using Equation (17), and the turbulence dissipation rate $\varepsilon$ can be obtained using Equation (18):

$$
\begin{gathered}
\frac{\partial}{\partial x_{i}}\left(\rho k \mu_{i}\right)=\frac{\partial}{\partial x_{j}}\left[\left(\mu+\frac{\mu_{i}}{\sigma_{k}}\right) \frac{\partial k}{\partial x_{j}}\right]+G_{k}+G_{b}+\rho \varepsilon-Y_{M} \\
\frac{\partial}{\partial x_{i}}\left(\rho \varepsilon \mu_{i}\right)=\frac{\partial}{\partial x_{j}}\left[\left(\mu+\frac{\mu_{i}}{\sigma_{\varepsilon}}\right) \frac{\partial \varepsilon}{\partial x_{j}}\right] G_{1 \varepsilon} \frac{\varepsilon}{k}\left(G_{k}+G_{3 \varepsilon} G_{b}\right)-C_{2 \varepsilon} \rho \frac{\varepsilon^{2}}{k}
\end{gathered}
$$

where $\sigma_{k}$ denotes the turbulent Prandtl coefficient in the kinetic equation $k$ [35]; $\sigma_{\varepsilon}$ is the turbulent Prandtl coefficient of dissipation rate in the $\varepsilon$ equation; $\mu_{t}$ is the turbulence viscosity; $G_{k}$ is the turbulence kinetics generated from the average speed gradient; and $G_{b}$ is the turbulence kinetics generated from buoyancy. Furthermore, $\mu_{t}=\rho C_{u} \frac{k^{2}}{\varepsilon}$ is calculated from the standard $k-\varepsilon$ equation, where $C_{u}=0.09$, $C_{1 \varepsilon}=1.44, C_{2 \varepsilon}=1.92, \sigma_{k}=1$, and $\sigma_{\varepsilon}=1.3$. 
(g) Standard wall function:

This equation was established based on the hypothesis of Launder and Spalding [36]. When the space-control nodes on the adjacent walls satisfy $y+>11.63$ and the fluid movement is located at the logarithmic rate layer, the fluid speed can be shown as follows:

$$
u^{+}=\frac{1}{\kappa} \ln \left(E y^{+}\right)
$$

where $u^{+}=\frac{u_{p}\left(C_{\mu}^{1 / 4} \kappa_{\rho}^{1 / 2}\right)}{\frac{\tau_{w}}{\rho}}$ and $y^{+}=\frac{\Delta y_{p}\left(C_{\mu}^{1 / 4} \kappa_{\rho}^{1 / 2}\right)}{\mu} . \kappa$ denotes the Karman constant, and $\kappa=0.41 ; E$ is the experience constant, and $E=9.81 ; u_{p}$ is the average speed of the fluid at point $p$; $k_{p}$ is the turbulence kinetic of point $p ; y_{p}$ is the distance between point $p$ to the wall; and $\mu$ is the kinetic viscosity coefficient of the fluid.

\subsubsection{Mesh System Selection}

The simulation was performed with an adaptive mesh refinement (AMR) function. Without influencing the precision of data simulation, the user can employ the AMR function for encryption by selecting the places with greater changes that they want to observe, such as where the velocity field or temperature field changes are great. The final mesh as constructed with AMR used 709,386 meshes and is displayed in Figure 2.

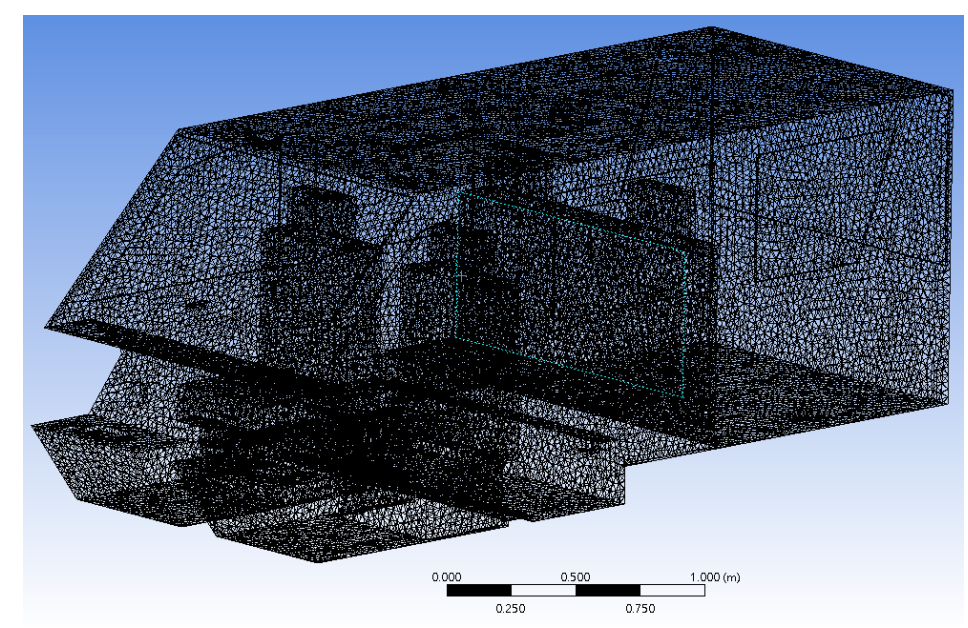

Figure 2. Car cabin constructed using adaptive mesh refinement (AMR).

\subsubsection{Regional AC System Simulation Settings}

The boundary conditions of the automobile cabin, including the various units such as the cabin AC inlet, outlet, and walls were as listed Table 1. The cabin regional AC system was simulated and analyzed using two cases involving different inlet and outlet boundary conditions. The inlet and outlet simulation settings are listed in Table 2.

Table 1. Boundaries of each unit in the cabin (for regional air-conditioning (AC)).

\begin{tabular}{cc}
\hline Boundary Name & Boundary Type \\
\hline Inlet Position & Velocity Inlet \\
Outlet Position & Pressure Outlet \\
Seat & Wall \\
Dashboard & Wall \\
Interior & Wall \\
Window & Wall \\
\hline
\end{tabular}


Table 2. Inlet and outlet simulation settings (for regional AC).

\begin{tabular}{ccc}
\hline Case & Inlet Settings & Outlet Settings \\
\hline A & Only turn on at the driver's seat & Only turn on at the driver's seat \\
B & Only turn on at the driver's seat & None (except for the blower outlet) \\
\hline
\end{tabular}

Case A was for the integrated regional AC system in the driver's seat. In the simulated cabin, only the driver required $\mathrm{AC}$, and therefore only the inlet and outlet at the driver's seat were open. The boundary of the cabin inlet was set as the velocity inlet. The wind speeds at Inlet 1 and Inlet 2 were 2.5 and $2 \mathrm{~m} / \mathrm{s}$, respectively; the temperature at both was $278 \mathrm{~K}$, and the inlet angles were $10^{\circ}$ and $55^{\circ}$, respectively (Figure 3a). For the outlet, the boundary condition was set as the pressure outlet, and the outlet pressure was $-75 \mathrm{~Pa}$ (Figure $3 b$ ).

Case B was for the driver's seat with no integrated regional AC system. Case B was similar to Case A in that only the driver required AC. However, Case B was different from Case A in that there was no integrated regional AC system, and therefore only the inlet at the driver's seat and outlet at the blower were open. The cabin inlet boundary condition was set as the velocity inlet. The wind speeds at Inlet 1 and Inlet 2 were 2.5 and $2 \mathrm{~m} / \mathrm{s}$, respectively; the temperature at both was $278 \mathrm{~K}$, and the inlet angles were $10^{\circ}$ and $55^{\circ}$, respectively (Figure $3 \mathrm{c}$ ). For the outlet, the boundary condition was set as the pressure outlet, and the outlet pressure was $-75 \mathrm{~Pa}$ (Figure $3 \mathrm{~d}$ ).

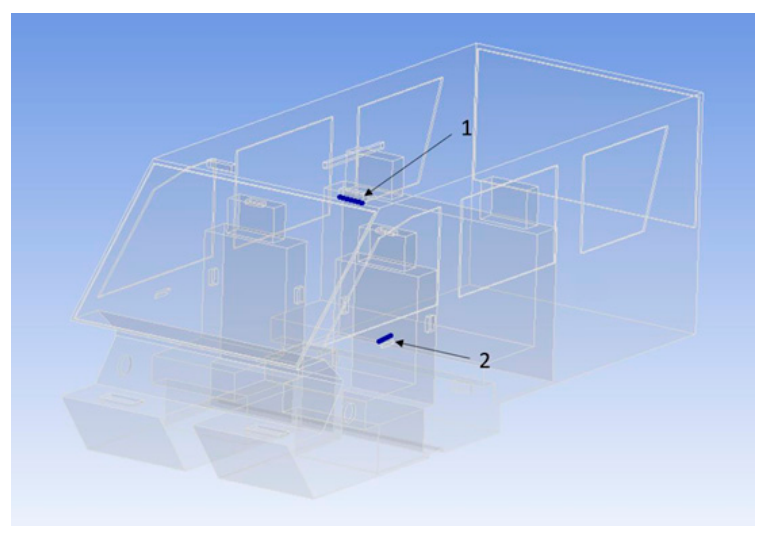

(a)

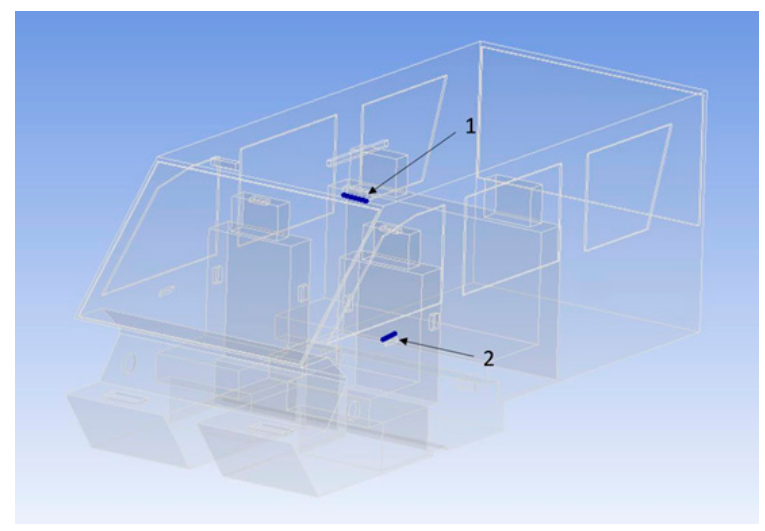

(c)

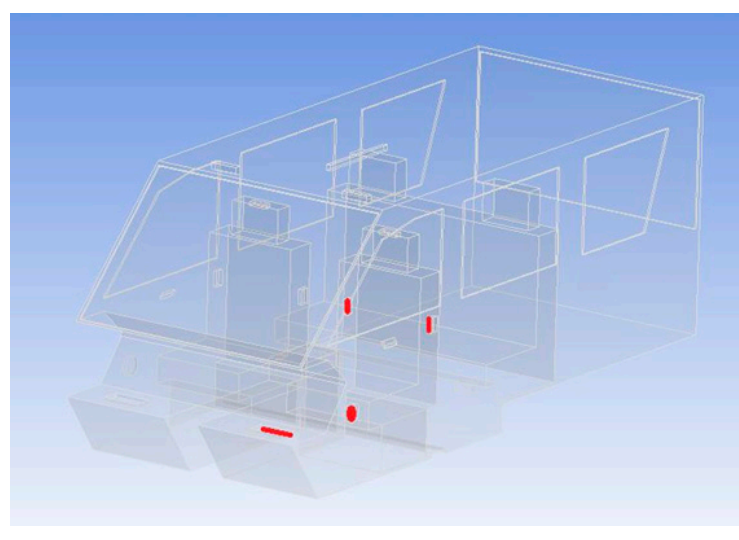

(b)

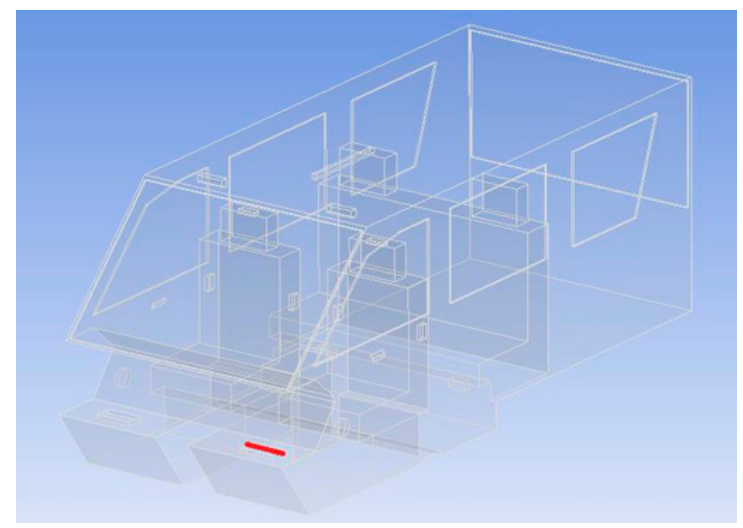

(d)

Figure 3. Case A (a) inlet locations and (b) outlet locations. Case B (c) inlet locations and (d) outlet locations.

Regarding the cabin boundary conditions, given that when the fluid passed the wall, the no-permeability and no-slip conditions were satisfied, the flow field was fixed to the wall. 
For example, the boundary conditions of the interior of the cabin and the window adopted the no-slip conditions. Therefore, the velocity of the flow field in all three directions was $0(v=v=\omega=0)$. Likewise, the fluxes of the turbulence kinetic energy, turbulent kinetic dissipation rate, and turbulence density that were vertical to the wall were all assumed to be zero $(\partial \mathrm{T} / \partial \mathrm{n}=\partial \varepsilon / \partial \mathrm{n}=\partial \mathrm{c} \partial \mathrm{n}=0)$. Regarding the external radiation, the ANSYS/FLUENT solar load model [33] was adopted using the typical fair weather conditions at the latitude and longitude of Taipei City. For the car, a BC type with an opaque body was adopted, and the windows were semitransparent. Detailed information is listed in Tables 3 and 4 .

Table 3. Solar radiation tracking module settings.

\begin{tabular}{cc}
\hline Item & Value \\
\hline Longitude & 121 \\
Latitude & 25 \\
Time zone & GMT +8 \\
Mesh Orientation & NORTH $(0,1,0)$ EAST $(1,0,0)$ \\
Starting Date and Time & June $13,13: 00$ \\
Solar Irradiation Method & Fair Weather Condition \\
Sunshine Factor & 1 \\
\hline
\end{tabular}

Table 4. Car cabin wall and window radiation boundary condition settings. IR is the abbreviation of infrared ray.

\begin{tabular}{lcc}
\hline \multirow{2}{*}{ Cabin Wall } \\
\hline \multirow{2}{*}{ Absorptivity } & Item & Value \\
\cline { 2 - 3 } & Direct Visible & 0.2 \\
\hline \multirow{2}{*}{ Absorptivity } & Direct IR & 0.8 \\
\cline { 2 - 3 } & Car Window & \\
\cline { 2 - 3 } & Item & Value \\
\hline \multirow{2}{*}{ Transmissivity } & Diffuse Hemispherical Visible & 0.1 \\
\cline { 2 - 3 } & Direct IR & 0.1 \\
\cline { 2 - 3 } & Direct Visible & 0.8 \\
\cline { 2 - 3 } & Diffuse Hemispherical & 0.8 \\
\hline
\end{tabular}

The initial condition assumed that the temperature in the cabin was $308 \mathrm{~K}$ and the car was idle. The AC operated at the set speed, temperature, angle, and inlet pressure in each case. The relaxation factors of Multiphysics were as follows: pressure $=0.3$, body forces $=1$, momentum $=0.7$, turbulence kinetic energy $=0.5$, turbulence dissipation rate $=0.5$, turbulence viscosity $=1$, and energy $=1$. Regarding the convergent conditions, the continuity, momentum, and turbulent equations were set to $10^{-3}$, whereas the energy equation was set to $10^{-6}$.

\subsubsection{Parking Ventilation System Simulation Settings}

The boundary condition of each ventilation unit in the cabin is listed in Table 5. Two models were separately used to conduct simulation in this study in order to assess cabin air quality and the ventilation monitoring system by setting two sets of outlet locations for analysis (Table 6). 
Table 5. Boundaries of each unit in the cabin (for parking ventilation).

\begin{tabular}{cc}
\hline Boundary Name & Boundary Type \\
\hline Inlet-Position & Pressure Inlet \\
Outlet-Position & Pressure Outlet \\
Seat & Wall \\
Dashboard & Wall \\
Interior & Wall \\
Window & Wall \\
\hline
\end{tabular}

Table 6. Inlet and outlet simulation settings (for parking ventilation).

\begin{tabular}{ccc}
\hline Case & Inlet Setting & Outlet Setting \\
\hline C & By the driver and front passenger doors & Underneath the backseats \\
D & By the driver and the front passenger doors & On the headliner \\
\hline
\end{tabular}

In Case $C$, the cabin inlet boundary condition was set as the pressure inlet. The external air temperature was $303 \mathrm{~K}$, and the pressure was $10 \mathrm{~Pa}$ (Figure 4a). The cabin outlet boundary condition was set as the pressure outlet. The outlet pressure was $-10 \mathrm{~Pa}$ (Figure $4 \mathrm{~b}$ ). In Case D, the cabin inlet boundary condition was set as the pressure inlet. The external air temperature was $303 \mathrm{~K}$, and the pressure was $10 \mathrm{~Pa}$ (Figure 4c). The cabin outlet boundary condition was set as the pressure outlet. The outlet pressure was $-10 \mathrm{~Pa}$ (Figure $4 \mathrm{~d}$ ).

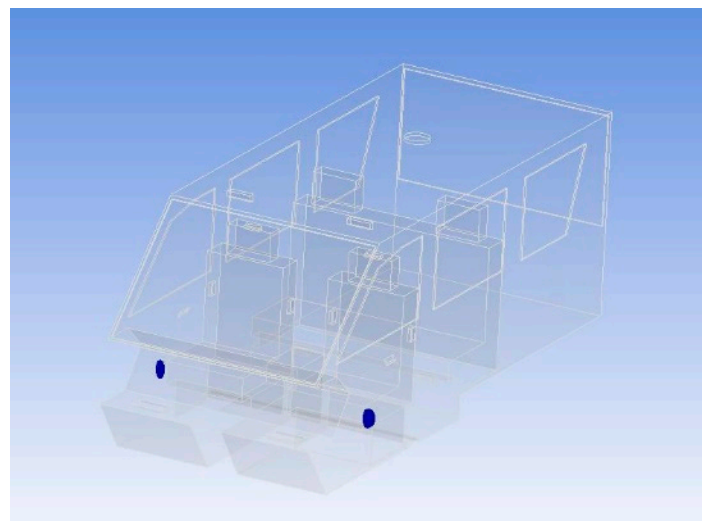

(a)

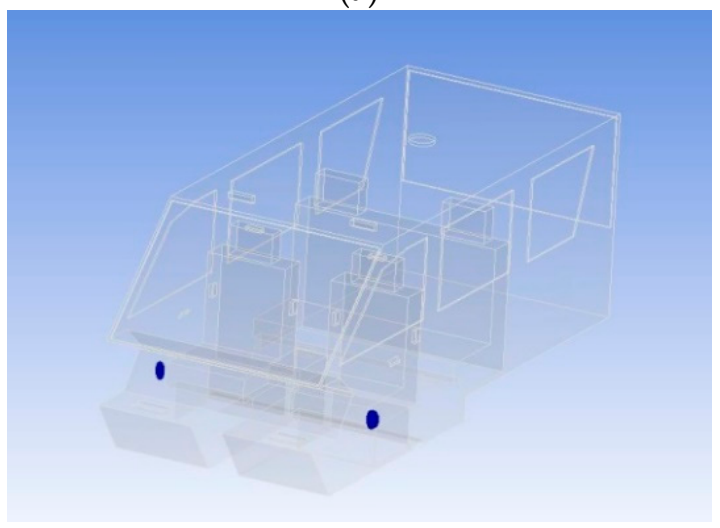

(c)

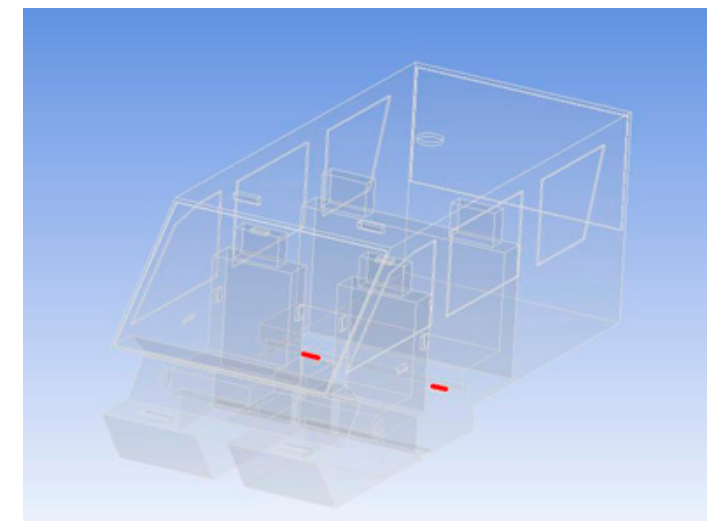

(b)

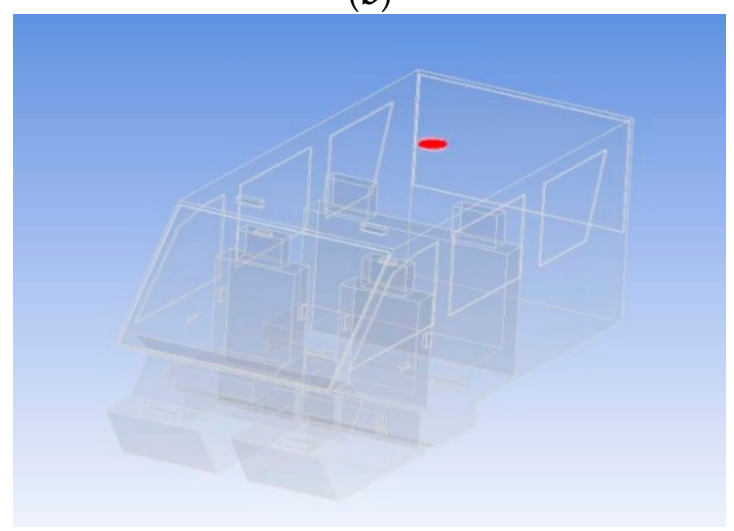

(d)

Figure 4. Case C (a) inlet locations and (b) outlet locations. Case D (c) inlet locations and (d) outlet location. 


\subsection{Experimental Data Measurement Platform}

Following the results of the cabin simulations, we renovated the AC system of a CMC Zinger, establishing new inlet, outlet, and control units to test and verify the effects of the proposed cabin energy conservation and ventilation system. The AC ventilator (VT-504, SHENG YUAN ELECTRIC Co., Ltd., Taichung, Taiwan) was used. Numerous types of data was recorded by a data collectro (cDAQ-9178, National Instruments Corp., Austin, TX, U.S.) together with a thermocouple module (NI9123, National Instruments Corp., Austin, TX, U.S.) and a voltage input module (NI 9201, National Instruments Corp., Austin, TX, U.S.) to create the data acquisition system. A T-type thermal couple was adopted, with a positive electrode made of bronze wire and a negative electrode made of copper-nickel alloy wire. This type of thermal couple can measure a range of -200 to $200{ }^{\circ} \mathrm{C}$ with high reusability. A differential pressure transmitter (CP101, KIMO Instrument, Chevry-Cossigny, France) was used. The wind velocity meter was a hot wire wind velocity meter (CTV 200, KIMO Instrument, Chevry-Cossigny, France).

\section{Results}

\subsection{Cabin Regional AC System Simulation}

Regarding the simulation results of Case A, Figure 5a,b show that the temperature was higher in areas with glass material. This was because, using the solar tracing model, solar radiation shot from the windows into the cabin. This did not affect the formation of the flow field structure. The temperature distributions in Figure 5a reveal that the AC temperature at the driver's seat did not disseminate to the other regions of the cabin. In addition, from the simulation of particle tracking in Figure $5 b$, it can be seen that the flow area of air conditioning is quite obvious falling in the driver's seat. This meant that the regional AC could construct an independent regional flow field, thereby avoiding AC disseminating to unoccupied regions and wasting energy. Therefore, the AC energy conservation need was met.

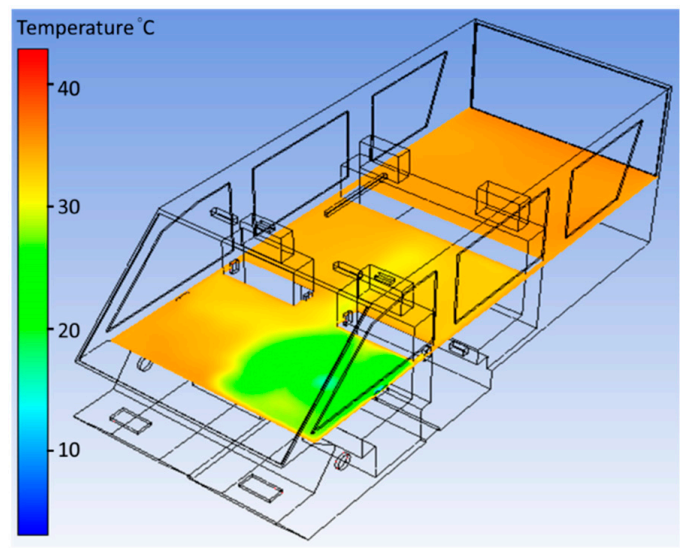

(a)

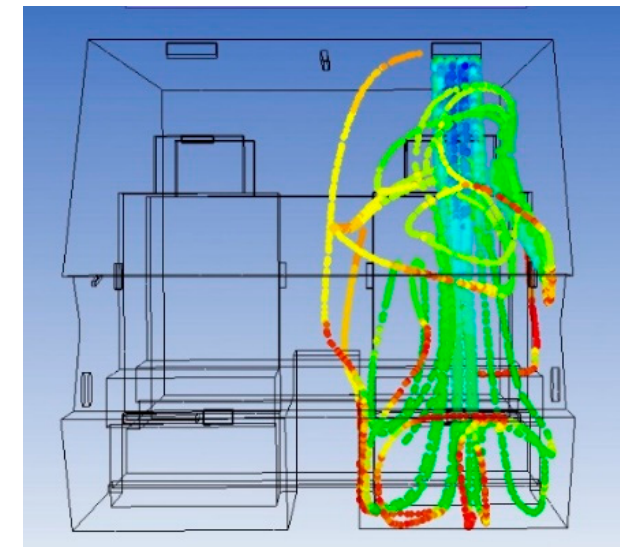

(b)

Figure 5. Case A simulation results of (a) temperature distribution profile of the entire car and (b) particle tracing.

Regarding the simulation results of Case B, the temperature distributions reflected in Figure 6a reveal that although the desired AC temperature at the driver's seat was reached, the energy disseminated to the front passenger's seat and other regions of the car. The situation can also be seen by the simulation of particle tracking in Figure $6 \mathrm{~b}$. The flow area of air conditioning is spread into the area outside the driver's seat. Thus, in Case B, an independent, regional flow field could not be constructed to avoid AC disseminating to unoccupied regions, causing energy waste. Therefore, a design without a pressure gradient guiding flow (outlet) cannot satisfy the AC energy conservation needs of a car with only the driver inside. 


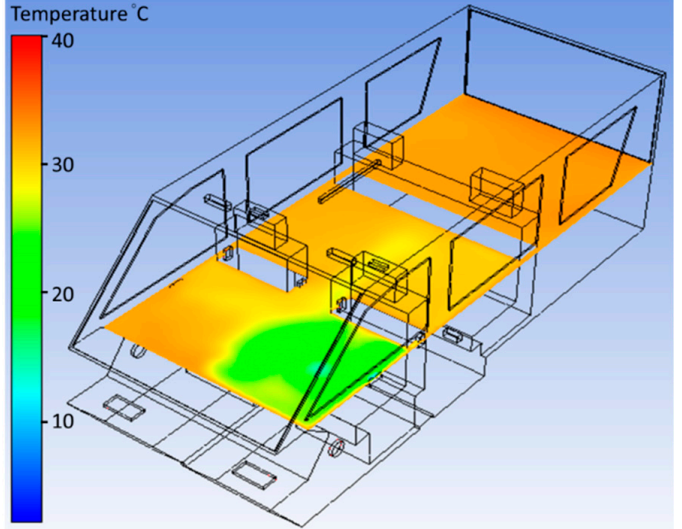

(a)

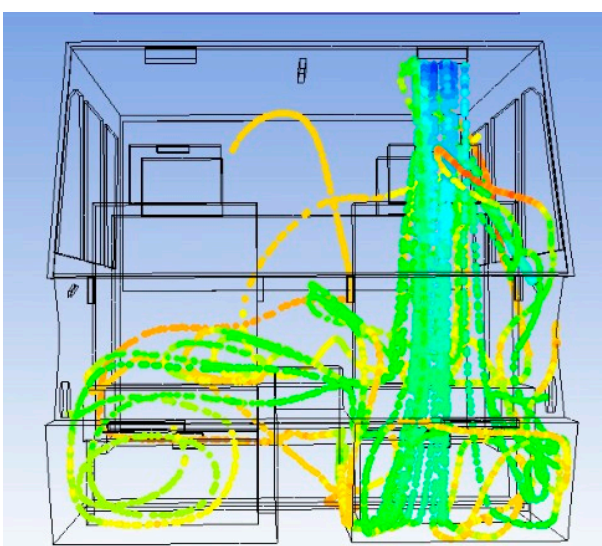

(b)

Figure 6. Case B simulation results of (a) temperature distribution profile of the entire car and (b) particle tracing.

\subsection{Parking Ventilation System Simulation}

The simulation results revealed that the temperature distribution of Case $\mathrm{C}$ in terms of heat load removal was suboptimal. The maximum temperature difference reached $9{ }^{\circ} \mathrm{C}$, which was higher than the goal. The results are illustrated in Figure 7. In Case D, the cabin temperature distribution was more even. The maximum temperature difference was only $2{ }^{\circ} \mathrm{C}$, meaning it achieved the heat load removal goal. The simulation results are shown in Figure 8.

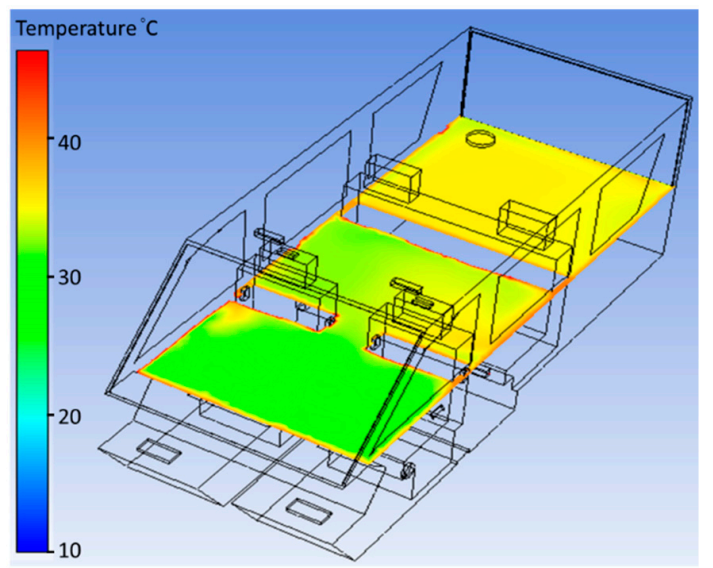

Figure 7. Case $\mathrm{C}$ simulation result of temperature distribution profile of the entire car.

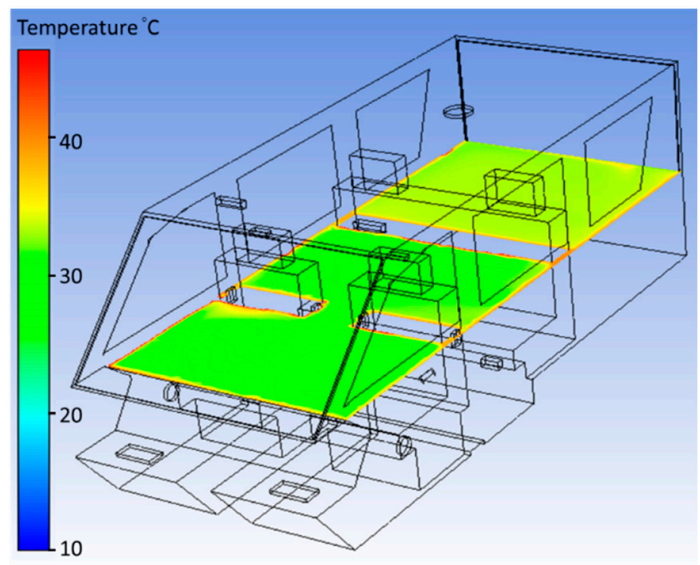

Figure 8. Case D simulation result of temperature distribution profile of the entire car. 


\subsection{Measurements from Cabin Experiments}

The experimental measurement platform was constructed according to the results from the numerical simulations for measuring the sensor information in Table 7.

Table 7. Cabin regional AC and parking ventilation system sensor location information.

\begin{tabular}{ccc}
\hline \multirow{2}{*}{ Thermocouple Number } & Cabin Regional AC System & Parking Ventilation System \\
\cline { 2 - 3 } & Location & Location \\
\hline 1 & Driver's seat-head & External air temperature \\
2 & Driver's seat-chest & Center of the car \\
3 & Driver's seat-legs & Driver's seat \\
4 & Left back passenger seat & Left back passenger seat \\
5 & Front passenger seat & Front passenger seat \\
6 & Right back passenger seat & Right back passenger seat \\
\hline
\end{tabular}

\subsubsection{Regional AC System Experimental Setting and Measurement Results}

The regional AC system was set to the conditions of Case $\mathrm{A}$, and experiments were conducted to measure two groups of data. The initial setting conditions were as presented in Table 8 , and the experimental results are shown in Figure 9a,b. After running the regional AC for $600 \mathrm{~s}$, the temperatures were measured, and they are listed in Table 9.

Table 8. Regional AC system measurement conditions.

\begin{tabular}{ccc}
\hline Item & Group 1 & Group 2 \\
\cline { 2 - 3 } & Value & Value \\
\hline Environmental temperature $\left({ }^{\circ} \mathrm{C}\right)$ & 29.5 & 35.5 \\
Inlet air velocity at the headliner of the driver's seat & 2.5 & 2.5 \\
Inlet air velocity at the driver's seat door & 2 & 2 \\
Negative pressure at the outlet $\left(\mathrm{Pag}_{\mathrm{g}}\right)$ & 75 & 75 \\
Weather condition & Cloudy & Sunny \\
\hline
\end{tabular}

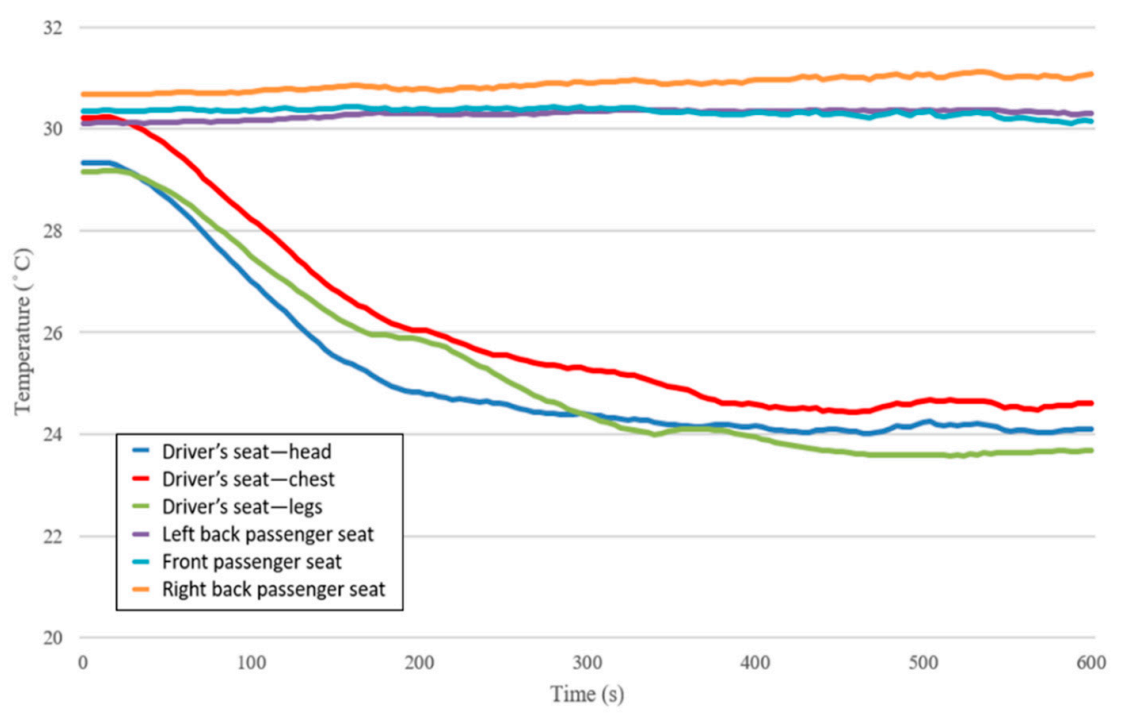

(a)

Figure 9. Cont. 
45

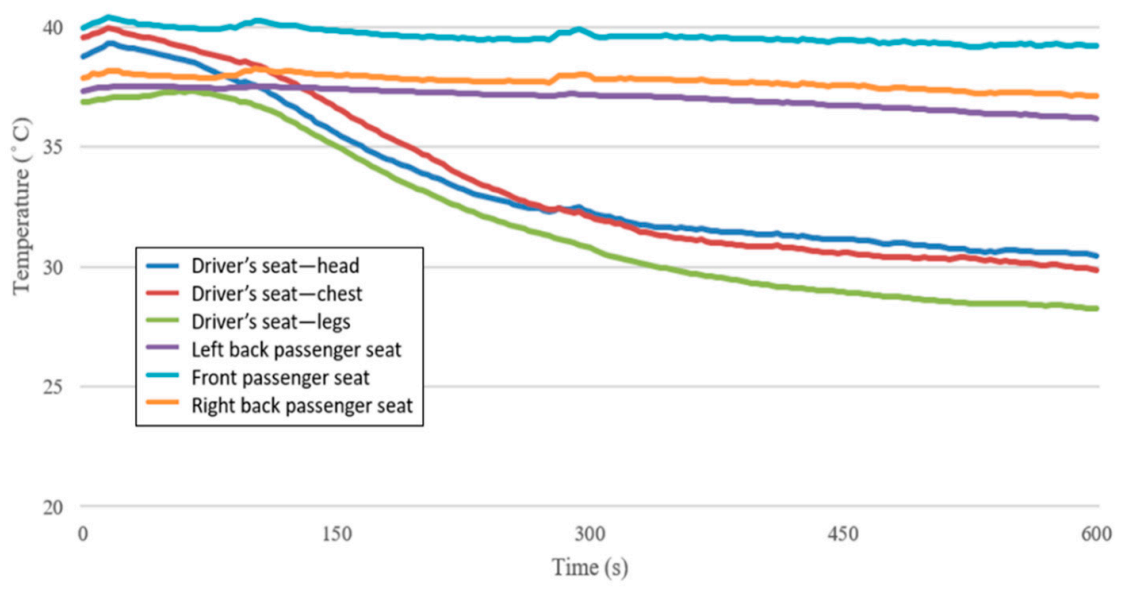

(b)

Figure 9. (a) Experimental results of the Group 1 regional AC system and (b) the Group 2 regional AC system.

Table 9. Final temperature at each measurement point in the regional AC system experiment.

\begin{tabular}{ccc}
\hline \multirow{2}{*}{ Thermocouple Location } & Group 1 & Group 2 \\
\cline { 2 - 3 } & Temperature $\left({ }^{\circ} \mathbf{C}\right)$ & Temperature $\left({ }^{\circ} \mathbf{C}\right)$ \\
\hline Driver's seat-head & 24.1 & 30.46 \\
Driver's seat-chest & 24.62 & 29.86 \\
Driver's seat-legs & 23.67 & 28.24 \\
Left back passenger seat & 30.3 & 36.18 \\
Front passenger seat & 30.16 & 39.22 \\
Right back passenger seat & 31.07 & 37.12 \\
\hline
\end{tabular}

3.3.2. Parking Ventilation System Experimental Setting and Measurement Results

The settings for Case D were also tested. The initial measurement conditions are shown in Table 10, and the experimental results are displayed in Figure 10. After running the cabin ventilation system for $1200 \mathrm{~s}$, the temperature at each point was measured, as listed in Table 11.

Table 10. Parking ventilation experimental conditions.

\begin{tabular}{cc}
\hline Item & Value \\
\hline Initial environmental temperature $\left({ }^{\circ} \mathrm{C}\right)$ & 30.81 \\
Negative pressure at inlet $(\mathrm{Pag})$ & 10 \\
Weather condition & Sunny \\
\hline
\end{tabular}

Table 11. Final temperature at each measurement point in the parking ventilation system experiment.

\begin{tabular}{cc}
\hline Thermocouple Location & Temperature $\left({ }^{\circ} \mathbf{C}\right)$ \\
\hline External air temperature & 29.73 \\
Center of the car & 30.24 \\
Driver's seat & 30.05 \\
Left back passenger seat & 30.69 \\
Front passenger seat & 30.55 \\
Right back passenger seat & 30.26 \\
\hline
\end{tabular}




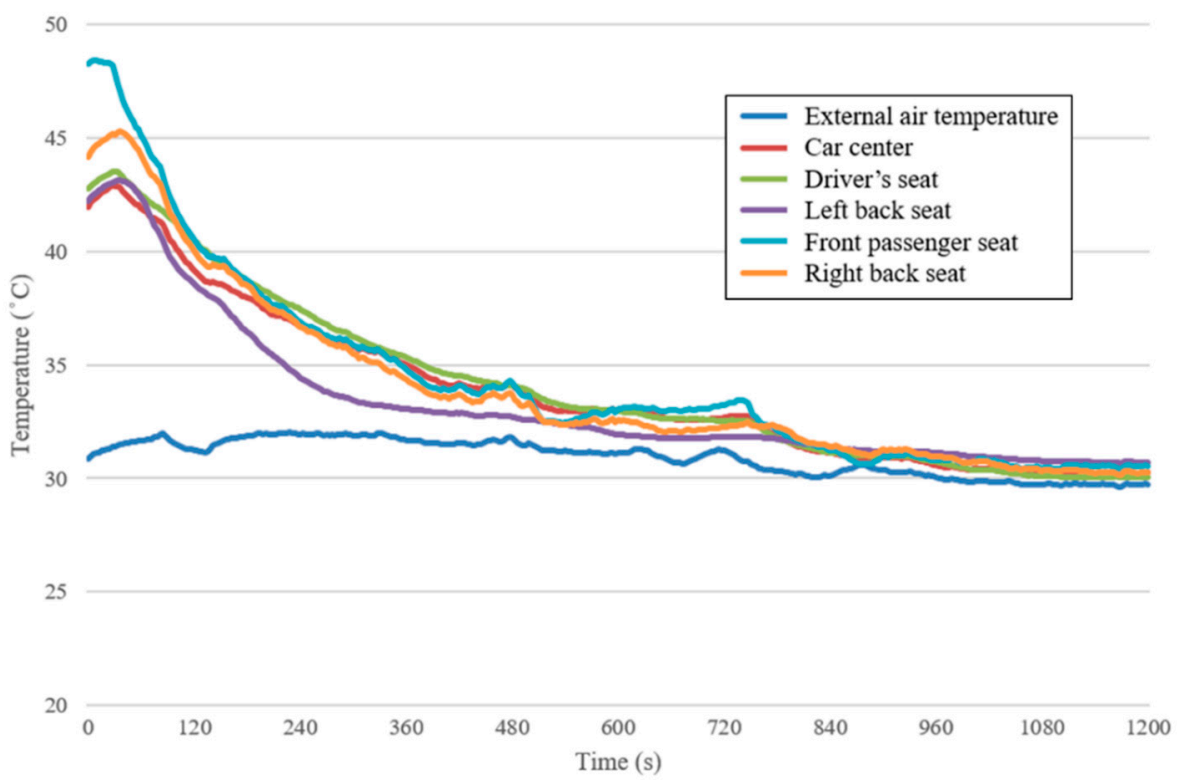

Figure 10. Temperature during the parking ventilation system experiment.

\section{Discussion}

\subsection{Regional AC and Parking Ventilation System Experiments}

The regional AC experiment for Group 1 started with an initial temperature of $29.5^{\circ} \mathrm{C}$. After $200 \mathrm{~s}$, the average temperature measured by the three sensors near the driver's seat $\left(25.57^{\circ} \mathrm{C}\right)$ exhibited clear differences from those at the other seats $\left(\sim 4-6{ }^{\circ} \mathrm{C}\right)$. After $400 \mathrm{~s}$, the temperature reduction gradually stabilized. By the end of the experiment after $600 \mathrm{~s}$, the temperature difference was approximately $6-7{ }^{\circ} \mathrm{C}$, demonstrating that the requirements for regional AC were satisfied. The same situation was observed in Group 2, which had a higher initial temperature. The final temperature difference was 7-9 ${ }^{\circ} \mathrm{C}$, which clearly demonstrated the strength of the regional AC. Finally, regarding the cabin ventilation system experiments, the initial average temperature in the cabin was $43.87{ }^{\circ} \mathrm{C}, 13^{\circ} \mathrm{C}$ higher than the environmental temperature of $30.87^{\circ} \mathrm{C}$. After $600 \mathrm{~s}$, the gap was reduced to $1.62{ }^{\circ} \mathrm{C}$. By the time the experiment ended after $1200 \mathrm{~s}$, the gap had been reduced to $0.7^{\circ} \mathrm{C}$, demonstrating that the cabin ventilation system could effectively resolve the dangers faced by people or pets trapped in a high-temperature cabin.

Comparing with the S-FLOW model [12] that opens a specific inlet selected by the driver, the power consumed by the electric compressor was $18.3 \%$ lower and the fuel consumption was $2.4 \%$ lower than the non-S-FLOW model when tested in summer. The power consumption was 36\% lower and the fuel consumption was 5.1\% lower when tested in spring and autumn (on a cloudy day without sunshine). Another previous result [14] using a cabin ventilation system and regional AC system showed that JIT enabled a $7^{\circ} \mathrm{C}$ decrease by $15 \mathrm{~min}$, which was similar to T-ctrl. However, T-ctrl consumed more power than JIS did because of longer start-up and turn-off times. Our design revealed a comparable improvement.

\subsection{Numerical Simulation and Experimental Verification}

To understand the error between the numerical simulations and experimental results, a comparison was conducted under a situation in which only the driver required AC. The inlet and outlet of the driver's seat were turned on. The experimental time was set to $600 \mathrm{~s}$. The final simulation and experimental results are shown in Table 12. 
Table 12. Comparison of experimental and simulation results.

\begin{tabular}{ccc}
\hline Thermocouple Location & Experimental Temperature $\left({ }^{\circ} \mathbf{C}\right)$ & Simulated Temperature $\left({ }^{\circ} \mathbf{C}\right)$ \\
\hline Driver's seat-head & 29.35 & 28.469 \\
Driver's seat-chest & 28.32 & 27.863 \\
Driver's seat-legs & 27.63 & 26.911 \\
Left back passenger seat & 36.18 & 35.295 \\
Front passenger seat & 39.22 & 36.311 \\
Right back passenger seat & 37.12 & 35.448 \\
\hline
\end{tabular}

A comparison of the experimental and simulation results revealed that the temperatures in the simulation were lower than those in the experiment, but only by an average of $3.75 \%$. This error can be attributed to the following two factors:

1. In the experimental cabin, when the temperature of the evaporator in the AC system reached the designated temperature, the clutch of the compressor would trip to avoid ice forming on the evaporator and resulting in AC failure. Therefore, the inlet temperature could not maintain the same value consistently, which could have caused minor differences between the simulation and experimental results.

2. The experimental location was situated in the basement surrounded by buildings. Sunlight that was not blocked by buildings was mainly focused on the front passenger and right back passenger seats of the experimental cabin. The solar radiation tracking modules used in the numerical analysis software accounted for the latitude, longitude, and time of solar radiation, and the angle of incidence and radiation thermal flux were different from those of the experimental location. Therefore, the simulation results for the front passenger seat differed slightly from those in the experiment.

\section{Conclusions}

The system proposed in this study could effectively achieve cabin energy conservation and cabin ventilation. We first employed a numerical analysis to obtain the effect of the AC system design on integrated regional $\mathrm{AC}$ and parking ventilation. After finalizing the design, we conducted experiments using a practical automobile. The conclusions we obtained from the numerical analysis and experimental validation are as follows:

1. Cabin regional AC technology: The design enabled the air flow field to be more evenly distributed around the selected occupied zone. The design used mathematical modeling for simulation of the inlet location, inlet angle, inlet air velocity, outlet location, and outlet negative pressure. Among them, the most critical factors were the inlet air velocity and air volume. Too large a figure would cause the flow field to disseminate, failing to form a regional flow field. An air velocity of $2 \mathrm{~m} / \mathrm{s}$ was therefore adopted, which could form an independent flow field space in the cabin with a temperature gap of $7{ }^{\circ} \mathrm{C}$ according to the user's needs. The inlet wind volume requirement was reduced by approximately $60 \%$ (from $300 \mathrm{~m}^{3}$ per hour to $120 \mathrm{~m}^{3}$ per hour), and the blower power was reduced by $53 \mathrm{~W}$ (from 68.4 to $15 \mathrm{~W}$ ).

2. Cabin ventilation technology: The inlet allocation should avoid using external air from the HVAC system. The ventilation duct is often on the inside of the engine compartment. Consequently, when external air enters, it is immediately heated, and it is unable to effectively reduce the temperature of the air in the cabin. We suggest that the outlet be placed at the headliner of the cabin. In addition to using mechanical means to exchange air (i.e., by using a ventilator), buoyance-driven ventilation theory should also be employed to speed up the removal of high-temperature air. In the present study, the air exchange rate reached approximately 89 air changes per hour, and the system could reduce the cabin temperature by $12.3^{\circ} \mathrm{C}$ in $20 \mathrm{~min}$. This rapid heat reduction can help prevent high temperatures from damaging the interior of the cabin and can also effectively prevent incidents such as in-cabin heatstroke, $\mathrm{CO}$ poisoning, and anoxia if someone is trapped inside the cabin. 
Author Contributions: Conceptualization, T.-C.Y. and P.-T.C.; methodology, T.-C.Y.; software, T.-C.Y.; validation, P.-T.C., T.-C.Y. and K.D.H.; formal analysis, T.-C.Y.; investigation, T.-C.Y.; resources, C.-J.Y.; data curation, T.-C.Y. and P.-T.C.; writing — original draft preparation, P.-T.C. and C.-J.Y.; writing—review and editing, P.-T.C. and C.-J.Y.; visualization, T.-C.Y.; supervision, P.-T.C. and K.D.H.

Funding: P.-T.C. thank the financial support from the Center of Atomic Initiative for New Materials (AI-Mat), National Taiwan University, Taipei, Taiwan from the Featured Areas Research Center Program within the framework of the Higher Education Sprout Project by the Ministry of Education (MOE) in Taiwan (108L9008).

Acknowledgments: Authors thank Editage Academic Editing for English editing.

Conflicts of Interest: The authors declare no conflict of interest.

\section{References}

1. Kristanto, D.; Leephakpreeda, T. Sensitivity analysis of energy conversion for effective energy consumption, thermal comfort, and air quality within car cabin. Energy Procedia 2017, 138, 552-557. [CrossRef]

2. Alahmer, A.; Mayyas, A.; Mayyas, A.A.; Omar, M.A.; Shan, D. Vehicular thermal comfort models; a comprehensive review. Appl. Therm. Eng. 2011, 31,995-1002. [CrossRef]

3. Croitoru, C.; Nastase, I.; Bode, F.; Meslem, A.; Dogeanu, A. Thermal comfort models for indoor spaces and vehicles-Current capabilities and future perspectives. Renew. Sustain. Energy Rev. 2015, 44, 304-318. [CrossRef]

4. Danca, P.; Vartires, A.; Dogeanu, A. An overview of current methods for thermal comfort assessment in vehicle cabin. Energy Procedia 2016, 85, 162-169. [CrossRef]

5. Zhou, X.; Lai, D.; Chen, Q. Experimental investigation of thermal comfort in a passenger car under driving conditions. Build. Environ. 2019, 149, 109-119. [CrossRef]

6. Qi, C.; Helian, Y.; Liu, J.; Zhang, L. Experiment study on the thermal comfort inside a car passenger compartment. Procedia Eng. 2017, 205, 3607-3614. [CrossRef]

7. Alahmera, A.; Omarb, M.; Mayyasb, A.R.; Qattawi, A. Analysis of vehicular cabins' thermal sensation and comfort state, under relative humidity and temperature control, using Berkeley and Fanger models. Build. Environ. 2012, 48, 146-163. [CrossRef]

8. Lee, J.W.; Jang, E.Y.; Lee, S.H.; Ryou, H.S.; Choi, S.; Kim, Y. Influence of the spectral solar radiation on the air flow and temperature distributions in a passenger compartment. Int. J. Therm. Sci. 2014, 75, 36-44. [CrossRef]

9. Pang, W.; Yu, H.; Zhang, Y.; Yang, H. Solar photovoltaic based air cooling system for vehicles. Renew. Energy 2019, 130, 25-31. [CrossRef]

10. Hu, Z.; Tan, G.; Li, Z.; Xu, H.; Huang, W.; Ye, Y. Solar Powered Vehicle Parking Ventilation System Pre-Cooling Analysis. SAE Tech. Pap. 2015. [CrossRef]

11. Kwon, C.; Lee, C.W.; Foster, L.; Kwon, J.; Shin, Y. Development of an energy- saving occupied-zone HVAC system (OZ HVAC). In Proceedings of the SAE 2012 World Congress \& Exhibition, Detroit, MI, USA, 24-26 April 2012.

12. Tabei, K.; Watanabe, M.; Doi, N.; Imai, K.; Young, S. Development of a S- FLOW System and Control (S-FLOW: Energy Saving Air Flow Control System. In Proceedings of the SAE 2013 World Congress \& Exhibition, Detroit, MI, USA, 16-18 April 2013.

13. Wang, M.; Wolfe, E.; Ghosh, D.; Bozeman, J.; Chen, K.H.; Han, T.; Zhang, H.; Arens, E. Localized cooling for human comfort. SAE Int. J. Passeng. Cars Mech. Syst. 2014, 7, 755-768. [CrossRef]

14. Jeffers, M.A.; Chaney, L.; Rugh, J.P. Climate Control Load Reduction Strategies for Electric Drive Vehicles in Warm Weather. In Proceedings of the SAE 2015 World Congress \& Exhibition, Detroit, MI, USA, 21-23 April 2015.

15. Alahmer, A.; Omar, M.A.; Mayyas, A.; Dongri, S. Effect of relative humidity and temperature control on in-cabin thermal comfort. Appl. Therm. Eng. 2011, 31, 2636-2644. [CrossRef]

16. Kambly, K.; Bradley, T.H. Geographical and temporal differences in electric vehicle range due to cabin conditioning energy consumption. J. Power Sources 2015, 275, 468-475. [CrossRef]

17. Marcos, D.; Pino, F.J.; Bordons, C.; Guerra, J.J. The development and validation of a thermal model for the cabin of a vehicle. Appl. Therm. Eng. 2014, 66, 646-656. [CrossRef] 
18. Torregrosa-Jaime, B.; Bjurling, F.; Corberán, J.M.; Di Sciullo, F.; Payá, J. Transient thermal model of a vehicle's cabin validated under variable ambient conditions. Appl. Therm. Eng. 2014. [CrossRef]

19. Simion, M.; Socaciu, L.; Unguresan, P. Factors which influence the thermal comfort inside of vehicles. Energy Procedia 2016, 85, 472-480. [CrossRef]

20. Alahmer, A.; Abdelhamid, M.; Omar, M. Design for thermal sensation and comfort states in vehicles cabins. Appl. Therm. Eng. 2012, 36, 126-140. [CrossRef]

21. Fojtlín, M.; Fišer, J.; Pokorný, J.; Povalač, A.; Urbanec, T.; Jícha, M. An innovative HVAC control system Implementation and testing in a vehicular cabin. J. Therm. Biol. 2017. [CrossRef] [PubMed]

22. Pokorny, J.; Fiser, J.; Jicha, M. Virtual Testing Stand for evaluation of car cabin indoor environment. Adv. Eng. Softw. 2014, 76, 48-55. [CrossRef]

23. Wu, J.; Jiang, F.; Song, H.; Liu, C.; Lu, B. Analysis and validation of transient thermal model for automobile cabin. Appl. Therm. Eng. 2017, 122, 91-102. [CrossRef]

24. Al-Zareer, M.; Dincer, I.; Rosen, M.A. Development and analysis of a portable compressed liquid air cooling system for fast vehicle cabin cooling. Int. J. Refrig. 2017. [CrossRef]

25. Mansour, C.; Nader, W.B.; Breque, F.; Haddada, M.; Nemer, M. Assessing additional fuel consumption from cabin thermal comfort and auxiliary needs on the worldwide harmonized light vehicles test cycle. Transp. Res. Part D 2018, 62, 139-151. [CrossRef]

26. Mao, Y.; Wang, J.; Li, J. Experimental and numerical study of air flow and temperature variations in an electric vehicle cabin during cooling and heating. Appl. Therm. Eng. 2018, 137, 356-367. [CrossRef]

27. Khayyam, H.; Kouzani, A.Z.; Hu, E.J.; Nahavandi, S. Coordinated energy management of vehicle air conditioning system. Appl. Therm. Eng. 2011, 31, 750-764. [CrossRef]

28. Chen, P.T.; Pai, P.H.; Yang, C.J.; Huang, K.D. Development of transmission systems for parallel hybrid electric vehicles. Appl. Sci. 2019, 9, 1538. [CrossRef]

29. Chen, P.T.; Shen, D.J.; Yang, C.J.; Huang, K.D. Development of a hybrid electric motorcycle that accords energy efficiency and controllability via inverse differential gear and power mode switching control. Appl. Sci. 2019, 9, 1787. [CrossRef]

30. Chen, P.T.; Nghia, D.D.; Yang, C.J.; Huang, K.D. Study of system integral energy efficiency of a hybrid pneumatic power system. Appl. Sci. 2019, 9, 2333. [CrossRef]

31. Chen, P.T.; Yang, F.H.; Gao, H.M.; Huang, K.D. Moderate energy for charging Li-ion batteries determined by first-principles calculations. Batter. Supercaps 2018, 1, 209-214. [CrossRef]

32. Chen, P.T.; Yang, F.H.; Cao, Z.T.; Jhang, J.M.; Gao, H.M.; Yang, M.H.; Huang, K.D. Reviving aged Lithium-ion batteries and prolonging their cycle life by sinusoidal waveform charging strategy. Batter. Supercaps 2019. accepted. [CrossRef]

33. ANSYS/FLUENT User's Manual, Release Version 14.5, 2012, Ansys Inc. Available online: https://www.ansys. com (accessed on 16 April 2019).

34. Chen, Q. Comparison of different $\mathrm{k}-\varepsilon$ models for indoor air flow computations. Numer. Heat Transf. Part $B$ Fundam. 1995, 28, 353-369. [CrossRef]

35. Lakkaraju, R.; Alam, M. Effects of Prandtl number and a new instability mode in a plane thermal plume. J. Fluid Mech. 2007, 592, 221-231. [CrossRef]

36. Patankar, S. Numerical Heat Transfer and Fluid Flow; CRC Press: Boca Raton, FL, USA, 1980.

(C) 2019 by the authors. Licensee MDPI, Basel, Switzerland. This article is an open access article distributed under the terms and conditions of the Creative Commons Attribution (CC BY) license (http://creativecommons.org/licenses/by/4.0/). 